2-ORIGINAL ARTICLE

\title{
A novel subcutaneous T-shaped bridge device for loop colostomies ${ }^{1}$
}

\author{
José Joaquim Ribeiro da Rocha ${ }^{\mathrm{I}}$, Marley Ribeiro Feitosa ${ }^{\mathrm{II}}$, Thiago Rodrigues da Cunha Stoianov ${ }^{\mathrm{III}}$, Camila Perazzoli ${ }^{\mathrm{IV}}$, Vanessa \\ Foresto Machadov, Mário Vinícius Angelete Alvarez Bernardes ${ }^{\text {VI }}$, Rogério Serafim Parra ${ }^{\text {VII }}$ Omar Féres ${ }^{\text {VII }}$
}

DOI: $h t t p: / / d x$. doi.org/10.1590/S0102-86502016001300002

IPhD, Associate Professor, Head of Division of Coloproctology, Department of Surgery and Anatomy, Ribeirão Preto Medical School, University of São Paulo. Design and development of bridge device. Critical revising and final approval of the version to be published.

IIMD, Division of Coloproctology, Department of Surgery and Anatomy, Ribeirão Preto Medical School, University of São Paulo. Conception and design of the study, acquisition of data, manuscript writing and manuscript review.

III Graduate Student, Ribeirão Preto Medical School, University of São Paulo. Acquisition of data and manuscript review.

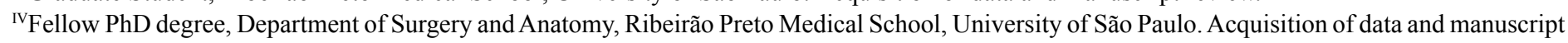
review.

${ }^{\mathrm{v} F e l l o w ~ P h D ~ d e g r e e, ~ D e p a r t m e n t ~ o f ~ S u r g e r y ~ a n d ~ A n a t o m y, ~ R i b e i r a ̃ o ~ P r e t o ~ M e d i c a l ~ S c h o o l, ~ U n i v e r s i t y ~ o f ~ S a ̃ o ~ P a u l o . ~ A c q u i s i t i o n ~ o f ~ d a t a ~ a n d ~ m a n u s c r i p t ~}$ review.

${ }^{\mathrm{V}}$ Fellow PhD degree, Department of Surgery and Anatomy, Ribeirão Preto Medical School, University of São Paulo. Acquisition of data and manuscript review.

VIIMD, PhD, Department of Surgery and Anatomy, Ribeirão Preto Medical School, University of São Paulo. Acquisition of data and manuscript review. VIIIPhD, Associate Professor, Department of Surgery and Anatomy, Ribeirão Preto Medical School, University of São Paulo. Design of the study, acquisition of data, critical revising and final approval of the version to be published.

\section{ABSTRACT}

PURPOSE: To describe a novel securing device for loop colostomies, developed in our institution and report our 10-year experience. METHODS: The T-shaped support device was used in all patients who required loop colostomy and who were at an increased risk of stoma withdrawal. The device was removed on the fifth postoperative day in all patients. An analysis from a prospective database regarding early postoperative complication, from 209 patients, was conducted between 2003 and 2013.

RESULTS: Bleeding, peristomal skin problems, surgical site infection, stomal ischemia/necrosis, stenosis, obstruction, retraction and early withdrawal of the stoma were not noted in all cases. Thirteen patients (6\%) reported mild discomfort on the site of the skin suture. Removal of the instrument was fast and easy, with the advantage of keeping the colostomy bag.

CONCLUSION: The T-shaped bridge device successfully prevented stoma withdrawal in all subjects. The device was safe and well accepted, with minor complications.

Key words: Surgical Stomas. Colostomy. Postoperative Complications. Medical Device. Inventions. 


\section{Introduction}

The creation of a stoma is an important and sometimes life-saving procedure. Any part of the colon can be used to build a stoma, depending on the indication. Colostomies are classified according to duration and which part of the colon opens on to the abdominal wall. The loop stomas are usually temporary and have an afferent (functioning) opening and an efferent (non-functioning) one. A Loop colostomy (LC) is usually created to divert fecal content from anastomoses with higher risk of dehiscence (e.g. coloanal anastomosis), distal obstruction, perineal sepsis or rectal trauma ${ }^{1}$. One of the common complications of LC is retraction, commonly caused by a poorly constructed stoma or obesity ${ }^{2}$. To minimize this complication a variety of instruments have been used to secure loop stomas in place, especially if excessive tension is suspected. The purpose of this manuscript is to describe our experience with a low-cost subcutaneous bridge device developed in our institution.

\section{Methods}

Our Institutional Review Board approved the present study. The instrument is a $10 \mathrm{~cm}$ long, T-shaped steel support, designed and developed by Dr. Rocha (patent PI0802729-3A2) (Figure 1). The device was inserted in the skin, at an adequate distance to avoid the colostomy bag. It was advanced subcutaneously and passed through the mesocolon of the exteriorized loop (Figure 2 ). The instrument was fixed to the skin with a simple nonabsorbable suture and removed on the fifth postoperative day in all patients. The bridge apparatus was used in two hundred and nine patients who underwent LC, between 2003 and 2013. We conducted an analysis of a prospective database of complications during hospitalization, which included the following parameters: bleeding, peristomal skin problems, surgical site infection, stomal ischemia/necrosis, stenosis, obstruction, retraction and early withdrawal of the stoma.

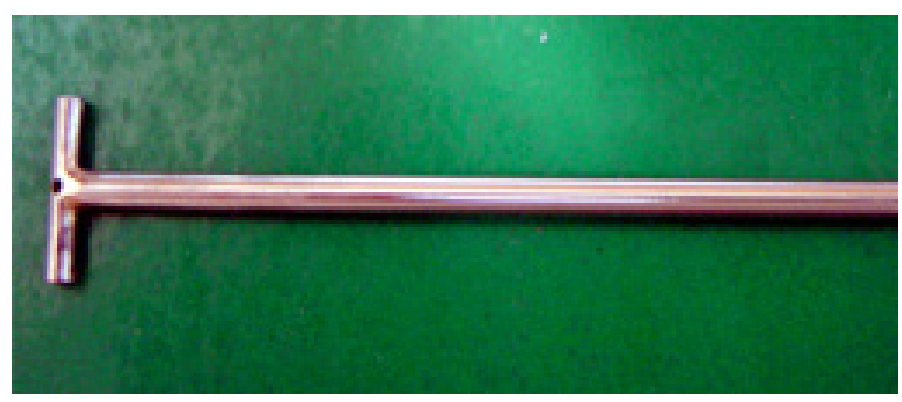

FIGURE 1 - T-shaped bridge device

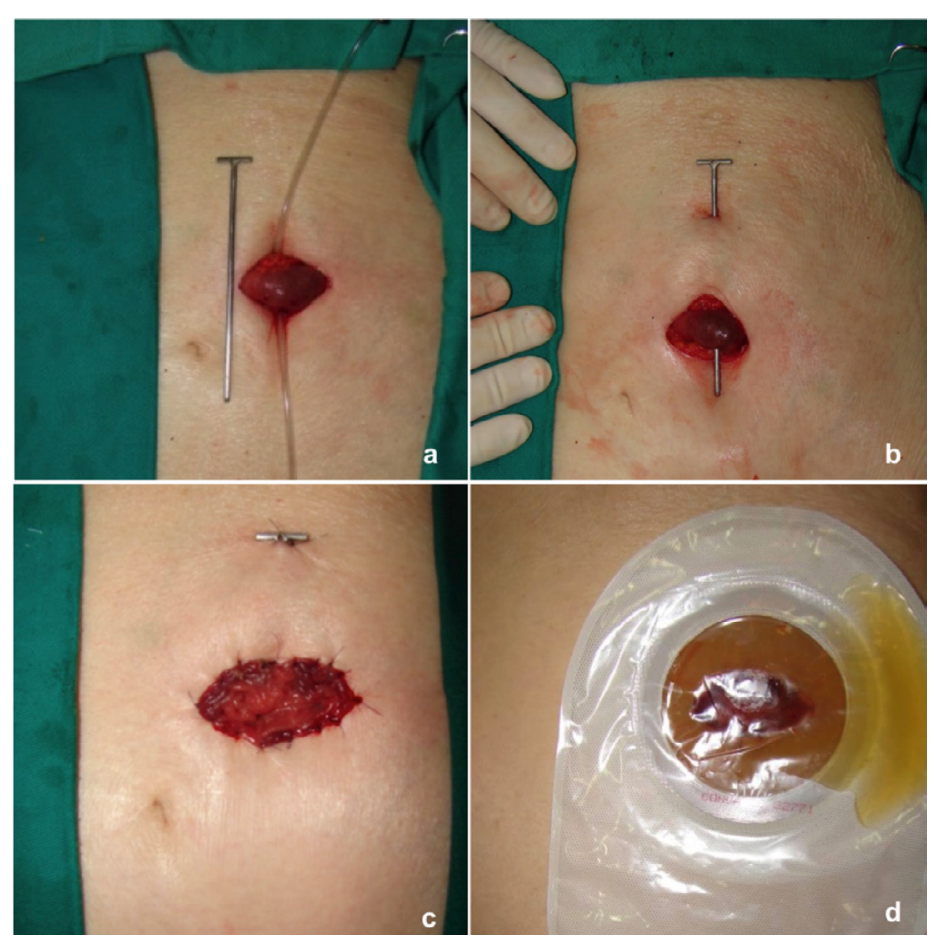

FIGURE 2 - Insertion of the bridge device. (A) Bridge device and exteriorized loop. An opening is made on the mesocolon where a narrow catheter is positioned. (B) The instrument is introduced in the skin and subcutaneously advanced through the mesocolon with the help of the previously mentioned catheter. (C) Suture of the bridge to the skin. (D) The colostomy bag is positioned.

\section{Results}

The bridge device was used in two hundred and nine patients. The group consisted of 111 (53\%) males and 98 (47\%) females. Average age of the patients was 66 years, ranging from 23 to 93 years. The indications for the colorectal surgery were: rectal cancer in $173(82.8 \%)$ cases, sigmoid cancer in $16(7.7 \%)$ cases, complicated diverticular disease in $6(2.9 \%)$ cases, megacolon in 5 (2.4\%) cases, complicated inflammatory bowel disease in $4(1.9 \%)$ cases, rectal endometriosis in $2(1.0 \%)$ cases and rectal trauma, rectal hemangioma and perineal sepsis in $1(0.5 \%)$ case, each. Mild pain on the site of the device was noted in $13(6 \%)$ cases. All other patients could not feel the device. Bleeding, infection, stenosis, ischemia, necrosis, retraction or premature withdrawal of the intestine were not noted.

\section{Discussion}

Creating the ideal stoma may be a challenging task for most surgeons. In fact, an actuarial analysis of 3970 stomas from UK identified a $34 \%$ rate of complications ${ }^{3}$. The most common early complications (presenting within 30 days of surgery) include: bleeding, infection, skin problems, stomal ischemia/necrosis, 
prolapse, retraction and withdrawal of the stoma ${ }^{4-7}$. Retraction is usually a result of tension on the maturated stoma and inadequate healing. To prevent this complication, a good mobilization of the colon is advised. Malnourishing, obesity and corticosteroid therapy are also considered as retraction risk factors ${ }^{7}$.

Colostomy rods have been used to secure stomasat risk of retraction. The main problem of those rods is that they do not lie flat against the skin, thus making it difficult to properly fit a colostomy bag. Rods are also big structures that may allow fecal discharge to become entrapped in the surgery site and predispose to serious infection ${ }^{8}$.

Milner et al. described a technique using a permanent skin bridge, by joining two inter-digitating skin flaps, sutured under the stoma9. They found no complications, however their series of 20 cases could be considered small. The disadvantages of a skin bridge include: a time consuming procedure, need for a plastic surgery in patients with potential cicatrization problems and higher risk of infection. Another group described a technique of a bridge using a redivac drain, placed subcutaneously, which had two points of fixation at the skin, and was removed between the $20^{\text {th }}$ and $30^{\text {th }}$ postoperative days ${ }^{10}$. Their group of 55 patients had a complication rate of $3.5 \%$ (peristomal hernia in a colostomy and prolapse of a ileostomy).

The advantage of our technique is that it is a fast procedure and only one anchoring point is needed, thereby decreasing patient's discomfort. Nevertheless, all complications in our group were related to the skin-anchoring suture. Peristomal infection and other skin problems were not a problem, mainly because the device had no contact with fecal content and the colostomy bag was always properly adapted. Removal of the instrument on the fifth postoperative day was safe and required only a pair of gloves and scissors to cut the skin suture.

Limitations of the present study lie on THE short followup period and lack of a control group. A randomized controlled trial comparing the present device to others would provide better scientific evidence. More studies with longer follow-up are also necessary, since post-operative complications may be noted after 5 days of the procedure, as noted by other authors ${ }^{3}$.

\section{Conclusion}

The present instrument was effective in preventing stoma retraction during the 5 first post-operative days, with low rates of complication.

\section{References}

1. Martin ST, Vogel JD. Intestinal stomas: indications, management, and complications. Adv Surg. 2012;46:19-49. PMID: 22873030.

2. Erwin-Toth P. Ostomy pearls: a concise guide to stoma siting, pouching systems, patient education and more. Adv Skin Wound Care. 2003;16(3):146-52. PMID: 12789037.

3. Cottam J, Richards K, Hasted A, Blackman A. Results of a nationwide prospective audit of stoma complications within 3 weeks of surgery. Colorectal Dis. 2007;9(9):834-8. PMID: 17672873.

4. Kann BR. Early stomal complications. Clin Colon Rectal Surg. 2008;21(1):23-30. PMID: 20011393.

5. Shellito PC. Complications of abdominal stoma surgery. Dis Colon Rectum. 1998;41(12):1562-72. PMID: 9860339.

6. Shabbir J, Britton DC. Stoma complications: a literature overview. Colorectal Dis. 2010;12(10):958-64. PMID: 19604288.

7. Kwiatt M, Kawata M. Avoidance and management of stomal complications. Clin Colon Rectal Surg. 2013;26(2):112-21. PMID: 24436659

8. Greene HG. Loop colostomy. Bar versus rod. Dis Colon Rectum. 1971;14(4):308-9. PMID: 5098290.

9. Milner CS, Sutton C, Hemingway D. The skin bridge loop colostomy. Tech Coloproctol. 2006;10(2):137-8. PMID: 16773285.

10. Baloyiannis I, Christodoulidis G, Symeonidis D, Hatzinikolaou I, Spyridakis M, Tepetes K. Loop stomas with a subcutaneously placed bridge device. Tech Coloproctol. 2010;14(1):S75-6. PMID: 20683745

\section{Correspondence:}

Marley Ribeiro Feitosa

Av. Bandeirantes, 3900 - Campus Universitário - Monte Alegre - $9^{\circ}$ andar 14048-900 - Ribeirão Preto, São Paulo, Brasil

Tel.: (55 16) 3602-2593

marleyfeitosa@yahoo.com.br

Conflict of interest: none

Financial source: none

${ }^{1}$ Research performed at the Division of Coloproctology, Department of Surgery and Anatomy, Ribeirão Preto Medical School, University of São Paulo. 